\title{
Perspectivas e desafios da coordenação de um programa de educação conjugal
}

\author{
Angélica Paula Neumann ${ }^{1}$ \\ Adriana Wagner ${ }^{2}$ \\ ${ }^{1}$ Universidade Regional Integrada do Alto Uruguai e das Missões - Campus de Erechim, RS, Brasil \\ ${ }^{2}$ Universidade Federal do Rio Grande do Sul, RS, Brasil
}

\begin{abstract}
Resumo
O estudo investiga as perspectivas e os desafios em coordenar o programa psicoeducativo para casais "Viver a dois: Compartilhando este desafio". Foram realizadas entrevistas em grupo com dez equipes de profissionais que conduziram o programa, totalizando 28 participantes. Os dados foram analisados por meio de Análise Temática no software NVivo. Os temas identificados denotam desafios na condução deste programa, como o estabelecimento da aliança terapêutica e o manejo de ocorrências imprevistas durante as oficinas, bem como a manutenção do equilíbrio entre o cumprimento das atividades conforme previsto pelo manual do programa e o estilo próprio de cada moderador. O programa também foi avaliado como um espaço que favorece novas possibilidades de trabalho com casais, em um formato lúdico e participativo. A possibilidade de oferecer uma intervenção de prevenção e promoção da saúde conjugal amplia o repertório de ações disponíveis aos profissionais que atuam nos mais diferentes contextos de trabalho.
\end{abstract}

Palavras-chave: Relações conjugais; Promoção da saúde; Intervenção psicossocial.

\section{Perspectives and challenges of coordinating a relationship education program}

\begin{abstract}
This study investigates the perspectives and challenges about coordinating the marital education program "Viver a dois: Compartilhando este desafio". Ten group interviews were completed with 28 health professionals who coordinated the program. Thematic analysis was performed with Nvivo software. Four themes were identified. The challenges were the establishment of therapeutic alliance, the need to deal with unexpected events and the need to keep a balance between the structured activities of the program and the coordinator's personal style. As perspectives, the program filled a gap in psychoeducational tools to work with couples by offering active and playful possibilities for the health professional who work with couples and families. The offer of interventions that focus on prevention and promotion of marital health broad the set of actions available to health professionals.
\end{abstract}

Keywords: Marital relations; Health promotion; Psychossocial intervention.

\section{Perspectivas y desafíos de la coordinación de un programa de educación conjugal}

\section{Resumen}

El estudio investiga las perspectivas y los desafíos para coordinar el programa psicoeducativo para parejas "Vivir en pareja: El arte de enfrentar los conflictos". Fueran realizadas entrevistas en grupo con diez equipos de profesionales que coordinaran el programa, totalizando 28 participantes. El tratamiento de los datos se hizo mediante análisis temáticos en el software NVivo. Los temas identificados denotan desafíos para la conducción de este programa, tales como el establecimiento de la alianza terapéutica y el manejo de situaciones imprevistas durante los talleres, así como el mantenimiento del equilibrio entre cumplir las actividades según lo previsto por el manual del programa y mantener el estilo propio de cada moderador. El programa también fue evaluado como siendo favorecedor de nuevas posibilidades de trabajo con parejas, en un formato lúdico y participativo. La posibilidad de ofrecer una intervención de prevención y promoción de la salud conyugal amplía el repertorio de acciones disponibles para los profesionales que actúan en los más diferentes contextos de trabajo.

Palabras clave: Relaciones de pareja; Promoción de salud; Intervención psicosocial. 
A educação conjugal consiste em um conjunto de estratégias destinadas a favorecer o aprimoramento das relações amorosas e a fomentar relacionamentos mais saudáveis, satisfatórios e estáveis (Halford \& Bodenmann, 2013). Tem sido desenvolvida por meio de programas estruturados e, usualmente, se baseia em dois pilares: o desenvolvimento de habilidades necessárias para a manutenção da qualidade da relação conjugal e a divulgação de conhecimentos sobre a vida a dois (Halford, Markman, Kline, \& Stanley, 2003).

Diferentemente das propostas psicoterapêuticas individualizadas, a maior parte dos programas de educação conjugal se propõe a trabalhar com grupos de casais, sob a coordenação de um ou mais profissionais moderadores (Owen, Manthos, \& Quirk, 2013). Desse modo, diversos temas são abordados, sendo os mais comuns as habilidades de comunicação, a aprendizagem da autorregulação emocional, o manejo de conflitos e as conexões positivas, tais como sexualidade, lazer e apoio (Wadsworth \& Markman, 2012).

A importância destes temas para a vida conjugal se reflete diretamente na complexidade que os profissionais enfrentam ao trabalharem tais conteúdos com os casais. Além do conhecimento técnico e teórico, é necessário que eles se sintam preparados e confortáveis para abordar temas íntimos de maneira imparcial, com casais que vivenciam diferentes formas de conjugalidade (Wagner et al., 2015). Por se tratar de um trabalho desenvolvido em grupo, também recai sobre os profissionais a necessidade de dominar e entender a dinâmica que se estabelece entre os participantes, manifestada pelas mais diversas reações, especialmente frente a temáticas delicadas e que dizem respeito à intimidade conjugal (Neumann \& Wagner, 2017).

É evidente, assim, a relevância de atentar para os profissionais que coordenam as ações de educação conjugal. Na literatura internacional, encontramse alguns dados acerca das características usuais e desejáveis dos moderadores desses programas. No que diz respeito à sua formação, é comum que os programas de educação conjugal sejam coordenados por psicólogos (Baucom et al., 2006), estudantes de psicologia (Markman, Floyd, Stanley, \& Storaasli, 1988) e estudantes de pós-graduação em psicologia clínica e aconselhamento psicológico (Owen et al., 2013, Zemp et al., 2017). Muitas intervenções relataram a participação de dois moderadores, sendo comum a co-coordenação de uma mulher e um homem (Quirk, Owen, Inch, France, \& Bergen, 2014).

Pesquisas demonstram que, quanto maior a aliança terapêutica entre moderador e participantes, melhores os resultados dos casais no que diz respeito à comunicação positiva, ao nível de comprometimento de cada membro do casal com o relacionamento e com a diminuição de interações negativas entre o casal (Ketring et al., 2017, Quirk et al., 2014). Outro estudo encontrou que a similaridade entre o nível educacional dos participantes e de, pelo menos, um dos moderadores, foi um preditor de mudanças no funcionamento individual dos participantes quanto ao manejo dos conflitos, à diminuição dos indicadores de depressão e ao aumento do sentimento de autoeficácia (Bradford, Adler-Baeder, Ketring, \& Smith, 2012). Nesse mesmo estudo, identificou-se que a semelhança entre o estado civil dos participantes e de, pelo menos, um dos moderadores, também foi um preditor do nível de mudança no funcionamento conjugal, reverberando na qualidade do relacionamento, no sentimento de felicidade, nas interações positivas e no ajustamento conjugal.

Como se pode perceber, mais do que a formação e o desempenho teórico-técnico dos profissionais moderadores, existem outros fatores relacionados à tarefa de coordenação que influenciam nos resultados percebidos pelos casais participantes de programas de educação conjugal. Considerando o ineditismo desse tipo de proposta no Brasil, é de grande relevância conhecer a experiência dos profissionais brasileiros que coordenaram as oficinas que compõem o programa de educação conjugal Viver a dois: Compartilhando este desafio (Wagner et al., 2015). Este programa tem como objetivo fomentar nos casais a ampliação do leque de estratégias utilizadas no enfrentamento de seus conflitos. É formado por seis oficinas realizadas em grupos de quatro a oito casais, com frequência semanal e duração variando entre $1 \mathrm{~h} 30$ e $2 \mathrm{~h}$ cada encontro. Os temas abordados pelo programa são mitos conjugais, conflito conjugal (temas, frequência, intensidade e estratégias de resolução), sexualidade e lazer a dois. Sua operacionalização envolve a participação ativa dos casais por meio de tarefas interativas, lúdicas e psicoeducativas. A Tabela 1 apresenta os objetivos e síntese das atividades de cada oficina. As atividades são conduzidas por profissionais de nível superior, com base em um manual que explica o passo a passo de cada oficina (Wagner et al., 2015). Algumas atividades podem ser realizadas individualmente no setting clínico, conforme recomendação do manual, uma vez que as técnicas disponíveis podem ser favorecedoras do processo de comunicação e resolução dos conflitos em terapias de casal. Entretanto, neste estudo se investigou a perspectiva dos profissionais que coordenaram $o$ programa em grupos de casais.

Explorar as percepções dos moderadores sobre o programa possibilita uma compreensão diferenciada 
dos processos que acontecem durante a sua execução, e envolve investigar tanto as possibilidades quanto os desafios vivenciados pelos moderadores durante estas ações. Estudos comprovam a capacidade do programa Viver a dois em auxiliar os casais no manejo de seus conflitos (Neumann \& Wagner, 2018), configurando-se, assim, como uma intervenção empiricamente sustentada que pode ser aplicada em diferentes contextos. Sabe-se que o Sistema Único de Saúde, por exemplo, preconiza o trabalho com grupos como forma de propiciar intervenções qualificadas a um maior número de indivíduos, fomentando também a criação de redes de apoio entre os usuários do sistema. Nesse sentido, o programa Viver a dois é uma ferramenta aplicável em contextos de saúde pública. Apesar disso, o trabalho com a conjugalidade nestes espaços, especialmente em uma perspectiva de prevenção e promoção de saúde, não possui tradição. Assim, explorar a experiência de profissionais que já realizaram o programa Viver a dois pode se constituir como uma ferramenta para a capacitação de profissionais que desejem conhecer e/ou aplicar o programa em seus contextos de trabalho. Frente a isso, este estudo tem como objetivo investigar as perspectivas e os desafios em coordenar o programa psicoeducativo para casais "Viver a dois: Compartilhando este desafio", segundo o relato de profissionais que trabalharam com tal tecnologia social.

TABELA 1

Descrição dos objetivos e atividades de cada oficina

\begin{abstract}
OFICINA 1: Reconhecimento da história do casal e a desconstrução dos mitos conjugais
Objetivos: Contribuir para o resgate da história do casal; Favorecer o conhecimento sobre a influência dos mitos na conjugalidade.

Atividade I: Trabalhando o autoconhecimento do casal. Por meio de uma apresentação, os participantes resgatam a história do casal.

A atividade possibilita que os cônjuges verbalizem sentimentos e emoções que possuem acerca do relacionamento.

Atividade II: Expectativas e mitos conjugais. Discute mitos socialmente construídos acerca das relações conjugais.

OFICINA 2: O conflito nosso de cada dia

Objetivos: Trabalhar a ideia de que os conflitos são inerentes ao cotidiano conjugal; Identificar quais os principais motivos de conflito na vida a dois; Proporcionar o autoconhecimento acerca do nível de tolerância frente aos diferentes temas de conflito que enfrentam;

Promover reflexões sobre as diferenças entre os cônjuges quanto ao enfrentamento dos conflitos, fomentando o respeito às diferenças.

Atividade I: $O$ termômetro dos conflitos. A partir desta atividade, cada díade dialoga sobre os motivos de conflitos que vivenciam no dia a dia e mensuram a intensidade com que cada cônjuge percebe estes desentendimentos.

Atividade II: Nossos conflitos de cada dia. No grande grupo, é realizada discussão acerca da prevalência de determinados temas de conflito no dia a dia conjugal.
\end{abstract}

\title{
OFICINA 3: Como lidar com os conflitos? As diferentes estratégias
}

Objetivos: Identificar e descrever as estratégias de resolução de conflitos mais frequentes no cotidiano conjugal; Favorecer o exercício de modulação do afeto vinculado aos conteúdos recorrentes nos conflitos; Promover o reconhecimento da forma como cada membro do casal se comunica e a reverberação dessa comunicação na conjugalidade.

Atividade I: Quando brigamos... Nesta atividade se trabalha a comunicação por meio da diferenciação entre o conteúdo daquilo que é verbalizado durante uma discussão e a forma como este conteúdo é expresso.

Atividade II: Identificação das estratégias utilizadas pelo casal. Por meio de atividade lúdica, os participantes aprendem quatro estratégias de resolução de conflitos e são instigados a identificar quais prevalecem em seus relacionamentos.

OFICINA 4: Aprendendo a negociar: A importância da flexibilidade

Objetivos: Ampliar a percepção de si, do(a) parceiro(a) e do quanto as características individuais se refletem no relacionamento conjugal; Desenvolver habilidades de empatia; Expandir o repertório de estratégias de negociação.

Atividade I: Ganhar-ganhar. Esta atividade mescla momentos psicoeducativos sobre negociação com tarefas nas quais cada díade precisa efetuar um acordo sobre tema importante para o relacionamento.

\section{OFICINA 5: Sexualidade: Um assunto para dois}

Objetivos: Favorecer que os casais reflitam sobre a sexualidade conjugal e a sua vivência sexual com o seu(a) parceiro(a); Estimular que os casais conversem entre eles sobre a sua sexualidade, enfocando os aspectos positivos e aqueles que apresentam dificuldades.

Atividade I: Mitos a respeito da sexualidade. São discutidos mitos socialmente construídos acerca da vivência da sexualidade.

Atividade II: Conversando sobre sexo. Atividade iniciada na oficina que encaminha os casais, para, em casa, dialogar sobre a forma como vivenciam a sexualidade em seu relacionamento.

OFICINA 6: Diversão a dois: A importância do lazer na vida conjugal

Objetivos: Favorecer a reflexão sobre a quantidade e a qualidade do tempo que o casal passa junto; Refletir sobre a capacidade de fazer escolhas satisfatórias a ambos; Oportunizar a redefinição do tempo de lazer que desfrutam juntos.

Atividade I: O que eu faço com meu tempo. Permite a visualização acerca da forma como cada membro do casal está utilizando o seu tempo o dia a dia.

Atividade II: Curtigrama do casal. Possibilita o diálogo acerca das atividades de lazer que os casais realizam ou gostariam de realizar. Atividade III: Despedida e contrato de intenções. Fechamento das oficinas por meio da realização de um contrato de intenções que expressa com o que cada membro de casal se compromete no relacionamento. 


\section{Método}

\section{Participantes}

Participaram deste estudo 28 profissionais da área da Psicologia, Educação, Saúde e Assistência Social, do sexo feminino, que coordenaram dez grupos do Programa Viver a dois: Compartilhando este desafio, abrangendo um total de 65 casais heterossexuais. Para tanto, as profissionais atuaram em equipes formadas por três integrantes, organizadas de acordo com os seguintes papeis: a) Moderadoras: profissionais que coordenaram as oficinas, assumindo um papel ativo na explicação das atividades e dos conteúdos psicoeducativos, bem como na condução das discussões grupais; b) Auxiliares: profissionais que auxiliaram as moderadoras na coordenação, assumindo um papel de maior distanciamento para observar a dinâmica do grupo, mas com autonomia para intervir complementando as colocações das moderadoras ou ressaltando aspectos que possam passar desapercebidos pela mesma; e c) Observadoras: profissionais que observaram o desenvolvimento das oficinas sem intervir em seu desenvolvimento. Dentre as participantes, 10 eram moderadoras, 9 eram auxiliares e 9 eram observadoras. Uma auxiliar e observadora não puderam participar da entrevista devido a conflito de horários.

A seleção das equipes que compuseram a amostra ocorreu por conveniência. As pesquisadoras divulgaram em suas redes de contato a busca por equipes de profissionais que atuassem nas áreas da Psicologia, Educação, Saúde, Direito e Assistência Social, as quais tivessem disponibilidade para a realização de um grupo do programa Viver a dois em seus locais de trabalho. As equipes que se candidataram foram entrevistadas para verificar a disponibilidade das mesmas e a viabilidade de realização do programa em seus contextos de trabalho. Assim, estavam habilitados a participar como moderadores, auxiliares ou observadores profissionais de diferentes áreas, devido ao entendimento de que o programa tem o potencial de ser utilizado em diferentes contextos.

As equipes atuavam em Secretarias de Saúde, Centros de Referência e de Referência Especializada em Assistência Social (CRAS e CREAS), Centros de Formação em Terapia de Família e Casal e Universidades, e estavam distribuídas em cinco cidades do sul do Brasil. Desta forma, houve participação de equipes atuantes em contextos de metrópole, região metropolitana, cidades do interior com mais de 100 mil habitantes e cidades do interior com menos de 20 mil habitantes. Para participar do estudo, as equipes participaram de treinamento sobre o Programa Viver a dois, com carga horária de $10 \mathrm{~h}$.
As equipes foram formadas apenas por mulheres devido às possibilidades dos contextos de trabalho $\mathrm{e}$ do interesse dos profissionais. Todas as moderadoras possuíam curso superior e nove delas possuíam ou estavam fazendo pós-graduação, sendo nove psicólogas e uma pedagoga. Sua média de idade foi de 36 anos $(\mathrm{DP}=10,35)$. Em sua maioria, eram casadas ou viviam em união estável $(60 \%, n=6)$. No momento da pesquisa, uma estava namorando (10\%) e três se declararam como solteiras $(30 \%)$. As auxiliares e observadoras possuíam curso superior $(57,8 \%, \mathrm{n}=11)$ ou eram estudantes de graduação $(42,1 \%, \mathrm{n}=8)$, atuando nas áreas de psicologia, assistência social, enfermagem e gestão pública. As médias de idade foram de 33 anos para as auxiliares $(D P=6,27)$ e 29 anos para as observadoras $(\mathrm{DP}=10,38)$. Também eram casadas ou viviam em união estável em sua maioria $(52 \%, \mathrm{n}=10)$, havendo uma parcela de participantes namorando $(26,3 \%, n=5)$, solteiras $(15,7 \%, n=3)$ ou separadas $(5,2 \%, n=1)$. Em todas as equipes haviam profissionais que, em sua vida pessoal, possuíam ou já tinham possuído experiência de coabitação.

\section{Instrumentos}

Realizou-se uma entrevista em grupo de caráter exploratório com cada equipe coordenadora. A entrevista em grupo consiste no uso de questionamentos de mais de um indivíduo simultaneamente, e pode ser utilizada para avaliar experiências compartilhadas pelos membros do grupo (Fontana \& Frey, 2005). Uma vez que as três integrantes da equipe participaram conjuntamente das oficinas, optou-se por esta modalidade de entrevista para oportunizar a construção conjunta dos dados. Este formato de entrevista permite que as respostas individuais sejam elaboradas a partir da resposta das demais participantes, possibilitando a complementação e o enriquecimento na produção das informações (Fontana \& Frey, 2005). Este enriquecimento ocorre pela identificação de concordâncias e divergências nas respostas dos participantes, favorecendo a reflexão sobre o tema no aqui e agora da entrevista. A entrevista foi realizada com base em um roteiro pré-definido, que investigou a experiência de coordenar um programa psicoeducativo para casais, o relacionamento entre a equipe, o relacionamento com os casais e os desafios identificados. As profissionais participantes também preencheram uma ficha de identificação contendo informações sociodemográficas.

\section{Procedimentos}

Contextualização. Este estudo integra uma investigação maior, com o objetivo de avaliar os indicativos de eficácia do programa Viver a Dois. Para 
tanto, as profissionais responderam a um checklist após cada oficina, na qual indicavam o quanto haviam realizado os procedimentos esperados para cada encontro. Além disso, mensuravam semanalmente indicativos de satisfação a respeito das oficinas.

Procedimentos de coleta de dados. Após o término das seis oficinas, foi realizada uma entrevista em grupo com cada equipe coordenadora, totalizando dez entrevistas. As entrevistas foram realizadas conjuntamente com moderadora, auxiliar e observadora, possibilitando o compartilhamento e a construção conjunta das informações (Fontana \& Frey, 2005). Todas foram conduzidas pela mesma pesquisadora, uma das autoras deste estudo. As entrevistas foram audiogravadas, com a permissão das participantes.

Procedimentos de análise dos dados. Após a realização das entrevistas, as mesmas foram transcritas na íntegra e revisadas, resguardando-se a identidade das participantes. Os dados foram analisados pelo método da Análise Temática (Braun \& Clarke, 2006), no software NVivo, versão 11. Foi realizada uma análise indutiva, de modo que o delineamento dos temas esteve diretamente relacionado aos dados do corpus. A análise foi realizada conforme os seguintes passos: 1) Familiarizando-se com os dados: realização de leitura ativa do data-set, buscando significados e padrões que indicassem possíveis temas. Nesta etapa, buscou-se identificar o maior número possível de temas abordados pelas participantes nas dez entrevistas; 2) Gerando códigos iniciais: com base nos indicativos da etapa anterior, realizou-se nova leitura do data-set, desta vez, codificando o texto. Nesta etapa, cada trecho das entrevistas foi codificado conforme as temáticas identificadas previamente; 3) Buscando temas: consistiu na análise dos códigos, que foram revisados exaustivamente na procura de similaridades e diferenças entre eles, até obter a formação dos temas, com seus respectivos excertos. Para tanto, não se considerou a quantidade de vezes em que um mesmo tema tenha sido citado, mas sim os aspectos que caracterizavam aquela resposta como distintiva das demais temáticas e com relevância para o escopo do estudo; 4) Revisando os temas: envolveu o refinamento dos conteúdos, por meio dos critérios de homogeneidade interna e heterogeneidade externa. Foram realizadas duas subfases: a) Os excertos de cada tema foram lidos e, quando necessário, recodificados, até se considerar que formavam um padrão coerente; b) $\mathrm{O}$ data-set foi relido na íntegra, para verificar se os temas eram representativos do data-set e se havia algum outro dado que podia ter passado despercebido anteriormente; 5) Definindo e nomeando temas: consistiu na descrição do escopo de cada tema; e 6) Produzindo o report: envolveu a descrição completa e detalhada dos temas, com a inclusão de excertos exemplificativos (Braun \& Clarke, 2006).

\section{Considerações éticas}

Este estudo foi aprovado pelo Comitê de Ética em Pesquisa do Instituto de Psicologia da Universidade Federal do Rio Grande do Sul, sob o número CAAE 43881515.6.0000.5334. Todas as profissionais participantes assinaram um Termo de Consentimento Livre e Esclarecido, assim como os casais que participaram dos grupos.

\section{Resultados}

A partir da Análise Temática, foram delineados quatro temas. O primeiro deles, Desafios relacionais, diz respeito às percepções das equipes acerca do relacionamento com os casais. O segundo tema, Desafios no cumprimento dos papeis, aborda os sentimentos das profissionais em relação ao desempenho dos papeis de moderadoras, auxiliares e observadores. Já o tema Desafios relacionados às reações dos casais reúne as reflexões acerca de situações consideradas obstaculizadoras do desenvolvimento do programa. Por fim, o tema Possibilidades do programa caracteriza as potencialidades e perspectivas deste para o trabalho com casais.

\section{Desafios relacionais}

O tema Desafios relacionais diz respeito às percepções das equipes acerca do relacionamento estabelecido com os grupos de casais. De forma geral, as equipes reportaram que estabeleceram uma boa relação com os participantes. No entanto, avaliaram que esta relação se deu conforme as características de cada grupo. Aqueles com maior proximidade entre os participantes também foram aqueles que desenvolveram maior proximidade com as coordenadoras:

"Moderadora 8 - (...) o vínculo que se constituiu foi muito bom, de muito carinho mesmo. De verdade. Eu fiquei chateada com o fim. (...)"

Por sua vez, os grupos que mantinham uma relação mais reservada entre si mantiveram este tipo de funcionamento também com as coordenadoras:

“Observadora 7 - Eu acho que foi tranquilo. (...) por exemplo, a... (participante, mulher) veio pedir orientação, um outro casal também veio depois pedir orientação, então criou vinculo, né? (...) de 
repente esse não conseguir se aproximar tanto (...) é em função do jeito do grupo funcionar, né?"

A dificuldade de vinculação com o grupo de casais apareceu no relato de uma das equipes investigadas. Por um lado, este aspecto foi atribuído às características do grupo. Por outro, foi justificado pelo impacto negativo que a execução de um programa estruturado gerou na espontaneidade da equipe moderadora. Uma vez que cada oficina possuía um roteiro bastante definido, com orientações claras acerca de quais aspectos deveriam ser abordados e discutidos, a equipe se sentiu inibida na condução das atividades, impactando na vinculação com o grupo.

\section{Desafios no cumprimento dos papeis}

A percepção acerca dos papeis específicos de moderadoras, auxiliares e observadoras, utilizados neste estudo, foi bastante discutida pelas profissionais participantes, que destacaram alguns desafios no seu cumprimento. Tais desafios serão abordados em três subtemas correspondentes, quais sejam, Papel de moderador, Papel de auxiliar e Papel de observador.

Papel de moderador. A experiência das profissionais que assumiram o papel de moderadoras dos grupos foi bastante diversificada. Um dos pontos que mais foi ressaltado pelas participantes se relacionou ao cumprimento do roteiro das oficinas, conforme assinalado anteriormente. Por se tratar de um programa estruturado, cada oficina possuía um roteiro que definia as atividades a serem realizadas, a sua ordem de realização e os aspectos que deveriam ser discutidos com o grupo a partir delas. Muitas moderadoras relataram dificuldades em relação a isso, alegando que o fato de haver um roteiro definido prejudicava a sua espontaneidade na condução do trabalho:

"Moderadora 2 - (...) porque eu tinha que cumprir com o manual. Então muitas vezes eu gostaria de fazer uma coisa e não fazia."

Apesar disso, ressaltaram a necessidade da existência do roteiro para a manutenção do foco das atividades:

"Moderadora 7-Mas o manual, assim, ele estrutura. E o maior desafio pra mim foi seguir a estrutura, não fugir daquilo. Porque é muito fácil. Eles puxam um assunto, $e$ (é muito fácil) entrar naquilo."

Frente a esse impasse entre o estilo próprio e a prescrição do manual, as moderadoras relataram a necessidade de adaptar as suas falas, expressando os conteúdos previstos de maneira própria e considerando o perfil e as demandas dos grupos:

"Moderadora 9 - (...) quando a gente citava exemplos a gente colocava o que estava ali no manual (...) e ai a gente perguntava se as pessoas entenderam, e tentava ir mediando, fazendo uma aproximação, né?"

As profissionais também falaram sobre o quanto se sentiram preparadas para coordenar as oficinas. Por um lado, dentre as profissionais que não possuíam formação e experiência específicas para o trabalho com casais, algumas relataram ter sentido falta de maior suporte teórico, por não ter subsídios para aprofundar a discussão:

"Moderadora 7 - (...) eu senti bastante dificuldade, por exemplo, eu sei que tinha o livro como aporte teórico. Mas, por exemplo... Acho que na quarta oficina (...) complementar aquilo pro moderador teoricamente (seria importante)."

Por outro lado, para as profissionais que possuíam formação e experiência específicas para o trabalho com casais, o desafio era distinguir entre aquilo que deveriam compartilhar e discutir com o grupo e aquilo que, apesar de compreenderem, não deveriam abordar:

"Moderadora 5 - Eu vi isso como um lado bom e um lado ruim, de ser terapeuta (de casais); o lado bom é que eu me senti super à vontade no manejo, do que ia vir, e realmente fui supertranquila para as oficinas. O outro lado é que, bom, dá vontade de explorar, e tu não pode, né? (...) E acho que o entendimento vai pra além e tu tem que poder trabalhar isso em ti, e não no grupo."

Papel de auxiliar. Em geral, as profissionais que atuaram no papel de auxiliares se mantiveram em um papel mais operativo, apresentando uma interação menor com o grupo:

"Auxiliar 2 - Eu senti que eu poderia ter me exposto mais. Ter me posicionado mais, agido mais, atuado, falado mais com o grupo, porque eu (...) me colocava realmente na posição de auxiliar, sabe? Quando solicitava eu auxiliava, ou eu entrava em algum momento, mas (...) no final eu senti que eu poderia ter feito mais."

Este funcionamento se deu, em partes, à orientação dada às profissionais no início da pesquisa acerca da 
divisão dos papeis na coordenação das oficinas, que permitia autonomia para as auxiliares, mas primando pela centralização da coordenação nas moderadoras. Apesar disso, algumas profissionais não se sentiram confortáveis neste papel, por não conseguir delimitar claramente até onde poderiam intervir. A fala de uma profissional que participou de dois grupos, primeiramente como auxiliar e depois como moderadora, ilustra esse sentimento:

"Moderadora 4 - Eu estava de auxiliar antes (no primeiro grupo) (...) e passei pra moderadora. (...) Agora eu consigo entender um pouco melhor qual é o papel de fato de estar ali auxiliando. Porque eu não me colocava tanto, eu achava que (...) quando era pra auxiliar, eu tentava desaparecer. (...) pra não sobrepor. E agora eu vejo que não. Porque (...) a gente fica muito presa ali no roteirinho (enquanto moderadoras). (...) Então por mais que tu mude as palavras ou não, tu precisa colocar (o que está previsto). Eàs vezes nesse seguir o roteiro, tu esquece de reforçar coisas que podem ser importantes, né? E eu acho que a Auxiliar $4 \mathrm{fez}$ isso brilhantemente (no segundo grupo). De fazer o gancho com a fala deles. Então eu acho que eu consigo ver muito mais hoje o poder do auxiliar. (...) é de repente reforçar um pouquinho mais alguns assuntos que pro grupo sejam interessantes, tu falar um pouquinho mais, se prender em algumas questões."

Papel de observador. Por sua vez, os observadores não relataram dificuldades na compreensão e desempenho do seu papel, porém, destacaram ter sido um desafio permanecer mais afastados, sem interagir verbalmente com o grupo:

"Observadora 8 - O primeiro dia foi horrivel, eu estava sentada na mesa assim... (demonstra uma postura de aproximação física ao grupo). $\mathrm{Na}$ (oficina) dos bonequinhos eu fiquei muito angustiada, parecia que eu tinha que ir lá ajudar. Nos outros, ai já foi mais tranquilo (...). Eu acho que para mim foi um exercício fantástico, né? Muitas vezes eu queria, 'bah, mas dava para falar isso', mas ai não dava né? (...). Mas eu acho que eu vivi junto, acho que foi uma experiencia legal nesse sentido. De estar de fora, mas vivenciando isso tudo. Acho que foi muito legal."

Apesar disso, valorizaram a oportunidade de observar os movimentos dos participantes de uma maneira mais livre, sem a necessidade de dar conta das demandas da coordenação:
"Observadora 4 - (...) nossa, dava pra ver muita coisa, né? Acho que pela leveza também do papel, né? Não tô ali cumprindo com o manual. Mas de poder observar o grupo, como é que eles estão sentados, se estão mais pertos, se estão mais próximos, se estão mais jogados, mais resistentes."

Em poucos grupos os observadores auxiliaram em alguma atividade pontual, tendo uma participação um pouco maior. Apesar disso, os grupos de casais os aceitaram bem. Alguns grupos demonstraram curiosidade em saber o que os observadores anotavam, mas, em sua maioria, aceitaram com facilidade o seu papel na equipe:

"Moderadora 3 - Eu acho que pra eles também ficou uma coisa bem clara, eles nunca pediram alguma coisa do tipo, pra Observadora 3, eles se dirigiam pra nós (...). E também não senti uma coisa persecutória, de ficar observando assim, embora a Observadora 3 tivesse que observar, eu dizia 'ah, ela tá me observando, então não se preocupem, a gente também tá sendo avaliadas, vocês estão nos ajudando...'."

\section{Desafios relacionados às reações dos casais}

Durante a realização do programa, diversas situações inesperadas aconteceram e foram consideradas pelas profissionais coordenadoras como obstaculizadoras do desenvolvimento do programa. Dentre essas situações, duas ocorreram com mais frequência: a desvalorização do(a) parceiro(a) e do relacionamento e a ocorrência de comportamentos considerados socialmente inadequados. A desvalorização do(a) parceiro(a) e do relacionamento aconteceu em alguns grupos e foi marcada pelo relato depreciativo de alguns participantes sobre o seu(sua) parceiro(a) ou sobre o relacionamento, ou pela exposição de questões de ordem privada e, por vezes, constrangedoras ao grupo:

\section{"Moderadora 11 - Ela lavou a roupa suja no grupo. De menosprezar."}

A ocorrência de comportamentos considerados socialmente inadequados diante do grupo também foi um dos comportamentos mais frequentes considerados pelas profissionais como obstaculizadores do processo. O que caracterizou tais comportamentos foi o não respeitar combinações de contrato de trabalho e/ou os demais participantes do grupo:

"Moderadora 6 - Saíram para atender telefone durante o grupo. Mesmo que a gente fizesse o contrato, 
assim, relembrasse que não pode chegar atrasado, eles não respeitavam muito. Essa questão de se sentir à vontade e no meio de uma fala não respeitavam muito e iam lá pegar um café, servia, sentava. $O$ modo de se sentar também, muito largado."

Outras cinco situações ocorreram com menor frequência, mas também foram consideradas delicadas pelos moderadores. A primeira delas diz respeito à fuga do tema de discussão, que ocorria especialmente em oficinas que abordavam temas densos, como sexualidade e conflito. Nessas situações, alguns casais passaram a falar de filhos ou utilizar de humor para abordar o tema, mantendo a discussão em um tom superficial:

"Moderadora 4 - Por outro lado, como eles eram bastante falantes, a dificuldade de manejo mesmo, de tentar ficar voltando o tempo todo para o tema, porque eles, em alguns momentos, até quebravam assim (a discussão), não sei se proposital ou não, quando o tema mexia, né? Um tema que a gente sentiu mais, foi sexualidade. (...) Então até uma tentativa de desmerecer o tema, sabe? (...) Teve um que contou uma piada, né? (...) Uma piada pejorativa".

A segunda situação diz respeito aos casais que, em alguma oficina em específico, vieram conflituados desde casa. Esta situação ocorreu poucas vezes, mas foi considerada pelas equipes como bastante difícil de manejar. De acordo com as equipes, além de os demais casais perceberem o clima emocional do casal conflituado, um nível alto de desentendimento dificultava que os parceiros conseguissem dialogar e refletir sobre os temas trabalhados:

"Moderadora 6 - Dois casais que vieram, um dos casais veio mais de uma vez brigados, e outro que veio um dia. (Os casais) estavam presentes, mas dificultaram um pouco a atividade, porque ai tu vai propor atividade e eles, né, entre eles não queriam se comunicar.

Observadora 6-E o grupo sente também, né?"

A centralização da discussão por algum casal também foi considerada uma situação de difícil manejo. Houve momentos em que algum casal do grupo centralizou a discussão em torno de questões pessoais, interferindo na realização de tarefas coletivas. Nessas situações, o próprio grupo passou a fazer movimentos para conter estes casais, dando-lhes menos espaço para falar sobre suas dificuldades:
"Observadora 2 - (...) no início eles falavam mais deles, mais coisas pessoais (...). Então tinha que (...) cortar eles para conseguir controlar a situação. Não deixar que eles se expusessem demais, mas também que não se sentissem mal, né?

Auxiliar 2 - Em alguns momentos, eu tinha a impressão de que alguns casais já não davam tanto espaço para que eles falassem. No início tinha mais escuta (...) e já nos outros momentos em que eles (...) falavam da própria relação (...) e das dificuldades, os outros casais já não davam tanta abertura."

Outra situação atípica e de difícil manejo ocorreu quando um casal trouxe filhos pequenos durante a realização de algumas oficinas, especificamente, aquelas que tratavam de temas densos, como conflito e sexualidade. Nesse sentido, os filhos foram percebidos pelas equipes como uma tentativa de dificultar a reflexão:

"Moderadora 7-Nós tínhamos um casal que há três encontros trazia um bebê de um ano e oito meses, né? Como é que tu vai falar sobre sexualidade com um bebê?

Auxiliar 7-Eassim, visivelmente para atrapalhar."

Por fim, outra situação considerada obstaculizadora foi a vinda de uma pessoa sozinha, sem o seu cônjuge. Mesmo com a combinação de que a participação na oficina poderia ocorrer apenas mediante o comparecimento de ambos os cônjuges, houve uma situação em que um dos parceiros chegou sozinho enquanto a oficina já acontecia, alegando que seu cônjuge em breve chegaria:

"Moderadora 6 - Ele chegou, e entrou, e chegou sozinho. E já tinha uns 15 minutos de oficina. (...) $E$ eu disse 'E a (participante, mulher)? Lembra que a gente tinha combinado?'. E ele: 'Não, ela já tá vindo'. Aí, eu fiquei assim 'será que eu tiro ele da sala?'. Porque iria causar um desconforto (...). Ai eu falei 'não, mas ela já tá chegando mesmo ou ela vai demorar? Porque vocês sabem que tem que fazer as atividades em conjunto'. E ai depois ela chegou. Mas foi um momento meio tenso, porque eu não sabia o que eu fazia naquele momento."

Em decorrência de situações como estas, os moderadores foram, algumas vezes, demandados a prover auxílio e orientação a alguns casais individualmente após as oficinas, encaminhando situações particulares. Em alguns casos, foi necessário efetuar encaminhamentos para terapia de casal. 


\section{Possibilidades do programa}

Mesmo com a percepção de diferentes desafios e obstáculos associados à coordenação do programa Viver a dois, as profissionais o avaliaram como uma tecnologia que proporciona uma gama de possibilidades na promoção de saúde dos casais. Em primeiro lugar, as participantes destacaram o programa como uma proposta inovadora, que permite novas maneiras de trabalhar com casais:

"Observadora 8 - Eu acho que foi muito rico (...). Foi uma experiência para nós, muito interessante. Exatamente porque é o outro lado do balcão, (...) nós estamos sempre do outro lado (i.e. atendimento clínico). Para mim abriu uma possibilidade enorme de trabalho, de possibilidades. De coisas que a gente não tinha se dado conta que dava para fazer."

Nesse sentido, as profissionais também ressaltaram que o formato do programa, contando com atividades práticas e participativas, foi algo marcante:

"Auxiliar 7 - A gente percebia nos casais, o material é bem elaborado. O fato, acho, de eles fazerem a atividade e não ficarem só no expositivo, acho que é muito bom. (...) você colocar no papel e pensar, por mais que tenha resistência deles, eles pensaram em algumas coisas, sem dúvida."

Há relatos acerca da importância do espaço proporcionado pelo programa como uma possibilidade de reflexão sobre a conjugalidade e de promoção de saúde:

"Moderadora 1 - Para mim ficou uma coisa muito nítida, do quanto é importante. De que seria importante todos os casais (participarem). A coisa da saúde, entendeu? Para mim o que mais marcou foi isso. (...) E eles falaram: 'quase todo mundo deveria ter isso, a gente comenta nas rodas de amigos'."

Esta possibilidade de intervir na vida conjugal dos casais, favorecendo o aprendizado de novas maneiras de vivenciar a conjugalidade, se estendeu a outros domínios da vida das profissionais. Elas destacaram a influência do programa na reflexão sobre a sua própria conjugalidade, bem como nas possibilidades de trabalho em instituições de saúde:

“Auxiliar 7 - (...) o programa é muito válido, ele é muito bom. Faz a gente pensar em coisas da gente, e também poder pensar sobre quem a gente tá atendendo. Porque assim, (...) a gente sabe que tem que trabalhar sexualidade, tem que trabalhar isso, tem que trabalhar aquilo, mas não existe nada estruturado ainda para atender (...) desta forma."

\section{Discussão}

O relato das profissionais que coordenaram o programa de educação conjugal Viver a dois: Compartilhando este desafio permitiu a identificação de quatro temas concernentes ao objetivo deste estudo, três associados aos desafios da coordenação de tais programas e um associado às suas possibilidades. O tema Desafios relacionais abordou o impacto da relação estabelecida entre as equipes coordenadoras e os casais no desenvolvimento do programa. Segundo a percepção das moderadoras, o desenvolvimento do vínculo foi permeado pelas características dos grupos, havendo grupos com maior e com menor proximidade das equipes. O vínculo emocional é um dos três componentes da aliança terapêutica, e diz respeito ao cuidado, confiança e conexão emocional entre clientes e profissionais (Bordin, 1979; McClintock, Perlman, McCarrick, Anderson, \& Himawan, 2017). Os outros componentes são o compartilhamento de objetivos e a concordância entre profissional e cliente a respeito das técnicas utilizadas no tratamento. $\mathrm{Na}$ experiência relatada pelas equipes, o vínculo emocional parece ter sido o elemento com maior variabilidade entre os grupos, exigindo maior atenção e cuidado por parte das moderadoras. Entretanto, estudos indicam que as características dos líderes contribuem em grande parte na formação da aliança terapêutica (Owen Rhoades, Stanley, \& Markman, 2011). Nesse sentido, reitera-se a necessidade de que os moderadores se sintam preparados para o trabalho com grupos e com casais, de modo que possam, dentro das circunstâncias, manejar adequadamente aqueles que apresentam níveis mais baixos de vinculação emocional.

O tema Desafios no cumprimento dos papeis diz respeito aos sentimentos das profissionais em relação aos papeis e demandas associadas à função de moderadoras, auxiliares e observadores. Para as moderadoras, o cumprimento das atividades conforme havia sido proposto no manual do programa foi considerado um dos principais desafios, impactando na aliança terapêutica. Neste estudo, este aspecto pareceu amplificado por questões relacionadas à metodologia da pesquisa. Uma vez que a aplicação do programa Viver a dois estava associada a um estudo de eficácia, havia a necessidade, e a consequente preocupação por parte das profissionais, de que as atividades fossem realizadas o mais próximo o possível das 
instruções contidas no manual do programa. Para que tal verificação fosse possível, logo após o término de cada oficina, moderadoras, auxiliares e observadoras assinalavam, a partir de um checklist, quais atividades haviam conseguido realizar, dentre todas as previstas. Entende-se que tal procedimento, necessário na fase atual de pesquisas sobre o programa, contribuiu para a sensação das moderadoras de se sentirem presas ao protocolo.

Nesse sentido, por um lado, ressalta-se a importância de seguir os passos apresentados no manual para que se possa cumprir com a proposta do programa, uma vez que os estudos de validação comprovam a sua capacidade de produzir melhoras nos níveis de conflitos conjugais a partir deste modelo estruturado de intervenção (Neumann \& Wagner, 2017; Neumann et al., 2018). Por outro lado, entende-se que atender à estrutura do programa não deve se sobrepor à espontaneidade e ao estilo pessoal dos moderadores. $\mathrm{O}$ estilo e a experiência de cada moderador é o que, muitas vezes, favorece o vínculo de confiança, pois faz a relação genuína. Tais características ganham importância ao se considerar que a capacidade do moderador de estabelecer uma aliança terapêutica é mediadora dos resultados que os casais irão obter em seu próprio relacionamento ao participar de ações de educação conjugal (Ketring et al., 2017, Owen et al., 2011, Quirk et al., 2014). Assim, ao iniciar um programa estruturado, tal como o Viver a Dois, uma das principais tarefas dos moderadores é a de conciliar a normatividade inerente a esse tipo de programa com a sua subjetividade e com a demanda do grupo de participantes, já que, inevitavelmente, cada profissional irá lançar mão dos seus recursos pessoais para se vincular ao grupo no desenvolvimento das tarefas.

De fato, coordenar um programa estruturado de educação conjugal envolve dar conta de uma grande variedade de elementos, que vão muito além das atividades programadas. $\mathrm{O}$ trabalho com grupos de casais pode originar uma grande variedade de respostas e reações por parte dos sujeitos (Neumann \& Wagner, 2017), algumas das quais de difícil manejo, o que constitui o terceiro eixo de desafios percebidos neste estudo. Diante disso, evidencia-se a importância de que o trabalho seja realizado em equipes e que se faça um acompanhamento com reuniões sucessivas a fim de planejar as estratégias e avaliar o processo. Um grande número de estudos corrobora tal perspectiva ao lançar mão de, pelo menos, dois profissionais na coordenação de programas de educação conjugal (Hurwich-Reiss, Rindlaub, Wadsworth, \& Markman, 2014). Destarte, os resultados apontam para a importância de que os auxiliares assumam um papel mais colaborativo e horizontal do que o proposto no presente estudo, o que pode contribuir para diminuir a sensação de sobrecarga dos moderadores.

Outro aspecto de grande relevância destacado pelos moderadores diz respeito à formação dos profissionais que coordenam o programa. Nesta amostra, a grande maioria das moderadoras eram psicólogas, havendo uma moderadora com formação em pedagogia. Dentre as auxiliares e observadoras, a formação era mais diversificada. Percebeu-se que, apesar da possibilidade de que profissionais de diferentes áreas realizassem o programa, houve predominância de participação de equipes que possuíam psicólogas, sendo estas escolhidas como moderadoras sempre que estivessem presentes na equipe. A despeito de esta ser uma amostra muito pequena para efetuar generalizações, não apareceram diferenças entre a equipe no que se refere ao desempenho de seu papel, em decorrência do tipo de curso de graduação acadêmica das moderadoras. Em estudos internacionais, percebe-se predominância de moderadores que estão em formação em terapia de casal (Owen et al., 2013, Zemp et al., 2017), embora alguns estudos relatem apenas que os moderadores foram treinados para aplicar o programa, sem especificar a sua formação original (Lucier-Greer, Adler-Baeder, Ketring, Harcourt, \& Smith, 2012).

No presente estudo, a maior diferença observada neste aspecto diz respeito à formação de pós-graduação, no caso, a especialização em terapia de casal. Parte das profissionais que não possuíam formação em terapia de casal relataram a necessidade de maiores subsídios teóricos. Já as moderadoras que eram especialistas em terapia de casal não relataram essa dificuldade, porém, ressaltaram a necessidade de estabelecer uma diferenciação constante entre aqueles aspectos observados no grupo que deveriam ser abordados e trazidos para a discussão, e aqueles que fugiam do escopo do programa, por adentrar em questões da individualidade dos casais, mais característicos no trabalho clínico. Assim, o desafio para o especialista em terapia de casal é o de não atuar como clínico, mas sim focalizar a dinâmica grupal buscando os aspectos transversais ao grupo, objetivando uma perspectiva de promoção e prevenção de saúde. Por sua vez, para os demais profissionais, evidencia-se a necessidade de maior preparação para o desenvolvimento do programa.

Apesar da existência de desafios, as participantes também destacaram o programa Viver a dois como uma tecnologia que amplia as possibilidades de trabalho com casais. No Brasil, a maior parte das intervenções com casais ocorre com um foco terapêutico, quando os problemas já estão instalados. Por mais que a prevenção e a promoção de saúde sejam elementos chaves das políticas públicas associadas ao Sistema Único de 
Saúde e ao Sistema Único de Assistência Social, ainda há pouco investimento em ações que trabalhem nessa perspectiva e com foco nas relações, especialmente as conjugais.

Nesse sentido, a possibilidade de oferecer intervenções com o foco na prevenção e promoção da saúde conjugal, em um formato que envolve atividades psicoeducativas e lúdicas, amplia o repertório de ações disponíveis aos profissionais que atuam nos mais diferentes contextos de trabalho. Pesquisas internacionais têm reunido evidências da eficácia dos programas de educação conjugal tanto para casais de níveis socioeconômicos médios e altos, quanto para casais em níveis baixos (McGill et al., 2016, Williamson, Altman, Hsueh, \& Bradbury, 2016, Zemp et al., 2016). Estudos acerca do programa Viver a dois também têm demonstrado a sua capacidade em produzir nos casais o aprendizado de novas formas de resolução dos seus conflitos (Neumann et al., 2018). Nesse sentido, investir na disseminação destas ações, bem como na capacitação de profissionais para utilizar o programa, é uma forma de investir em promoção e prevenção de saúde familiar.

Os relatos deste estudo dizem respeito à primeira experiência de aplicação do programa Viver a dois pelas equipes participantes. Apenas duas equipes entrevistadas haviam realizado o programa mais de uma vez. Nesse sentido, os resultados aqui apresentados podem ser de grande utilidade para profissionais interessados em aplicar o programa Viver a dois em seus contextos laborais, uma vez que descrevem situações que podem ocorrer durante a aplicação do programa. Da mesma forma, tais resultados podem ser utilizados para refletir sobre a oferta de outras modalidades de intervenção em grupo, especialmente intervenções estruturadas.

Dentre as limitações desse estudo, ressalta-se que a amostra é de tamanho pequeno e se concentra na região sul do país. Assim, apesar de ter havido variação no nível socioeconômico e cultural dos casais participantes, os resultados não podem ser generalizados para toda a diversidade cultural brasileira. Também é necessário considerar que, em sua maioria, as equipes realizaram apenas um grupo. Desta forma, estudos similares com equipes mais experientes poderiam produzir resultados diversificados. Além disso, uma limitação importante é a presença apenas de profissionais mulheres como partes das equipes. Considera-se que equipes mistas poderiam resultar em processos diferentes daqueles que apareceram nesse estudo.

\section{Referências}

Baucom, D. H., Hahlweg, K., Atkins, D. C., Engl, J., \& Thurmaier, F. (2006). Long-term prediction of marital quality following a relationship education program: Being positive in a constructive way. Journal of Family Psychology, 20(3), 448-455. https://doi.org/10.1037/0893-3200.20.3.448

Bordin, E. S. (1979). The generalizability of the psychoanalytic concept of the working alliance. Psychotherapy: Theory, Research, \& Practice, 16, 252-260. https://doi.org/10.1037/h0085885

Bradford, A. B., Adler-Baeder, F., Ketring, S. A, \& Smith, T. A. (2012). The role of participant-facilitator demographic match in couple and relationship education. Family Relations, 61(1), 51-64. https://doi.org/10.1111/j.17413729.2011.00679.x

Braun, V., \& Clarke, V. (2006). Using thematic analysis in psychology. Qualitative Research in Psychology, 3(2), 77-101. https://doi.org/10.1191/1478088706qp063oa

Einhorn, L., Williams, T., Stanley, S. M., Wunderlin, N., Markman, H. J., \& Eason, J. (2008). PREP inside and out: Marriage Education for inmates. Family Process, 47(3), 341-56. https://doi.org/10.1037/0022-006X.56.2.210

Fontana, A. \& Frey, J. H. (2005). The interview: From neutral stance to political involvement. In N. K. Denzin \& Y. S. Lincoln (Eds.). The SAGE handbook of qualitative research (pp. 695-727). London: SAGE Publications, Inc.

Halford, W. K. \& Bodenmann, G. (2013). Effects of relationship education on maintenance of couple relationship satisfaction. Clinical Psychology Review, 33(4), 512-525. https://doi.org/10.1016/j.cpr.2013.02.001

Halford, W. K., Markman, H. J., Kline, G. H., \& Stanley, S. M. (2003). Best practice in couple relationship education. Journal of Marital and Family Therapy, 29(3), 385-406. https://doi.org/10.1111/j.1752-0606.2003.tb01214.x

Hawkins, A. J., Stanley, S. M., Blanchard, V. L., \& Albright, M. (2012). Exploring programmatic moderators of the effectiveness of marriage and relationship education programs: A meta-analytic study. Behavior Therapy, 43(1), 77-87. https://doi.org/10.1016/j.beth.2010.12.006

Hurwich-Reiss, E., Rindlaub, L. A., Wadsworth, M. E., \& Markman, M. J. (2014). Cultural adaptation of a family strengthening intervention for low-income Spanish-speaking families. Journal of Latina/o Psychology, 2(1), 21-36. https://doi.org/10.1037/lat0000010

Ketring, S. A., Bradford, A. B., Davis, S. Y., Adler-Baeder, F., McGill, J., Smith, T. A. (2017). The role of the facilitator in couple relationship education. Journal of Marital and Family Therapy, 43(3): 374-390. https://doi.org/10.1111/ jmft.12223 
Lucier-Greer, M., Adler-Baeder, F., Ketring, S. A., Harcourt, K. T., \& Smith, T. (2012). Comparing the experiences of couples in first marriages and remarriages in couple and relationship education. Journal of Divorce \& Remarriage, 53(1), 55-75. https://doi.org/10.1080/10502556.2012.635970

Markman, H. J., Floyd, F. J., Stanley, S. M., \& Storaasli, R. D. (1988). Prevention of marital distress: A longitudinal investigation. Journal of Consulting and Clinical Psychology, 56(2), 210-217. https://doi.org/10.1111/j.15455300.2008.00257.x

McClintock, A. S., Perlman, M. R., McCarrick, S. M., Anderson, T., \& Himawan, L. (2017). Enhancing psychotherapy process with common factors feedback: A randomized, clinical trial. Journal of Counseling Psychology. Advance online publication. https://doi.org/10.1037/cou0000188

McGill, J., Adler-Baeder, F., Bradford, A. B., Kerpelman, J., Ketring, S. A., Sollie, D. (2016). The role of relational instability on individual and partner outcomes following couple relationship education participation. Family Relations 65(3), 407-423. https://doi.org/10.1111/fare.12201

Neumann, A. P., Mosmann, C. P., \& Wagner, A. (2015). Viver a dois: É possível educar para a conjugalidade? In A. Wagner, D. Falcke, \& C. P. Mosmann. Viver a dois: Oportunidades e desafios da conjugalidade (pp. 101-112). São Leopoldo: Editora Sinodal.

Neumann, A. P., Wagner, A., \& Remor, E. (2018). Couple relationship education program "Living as Partners": evaluation of effects on marital quality and conflict. Psicologia: Reflexão e Crítica, 31(26). https://doi.org/10.1186/s41155-018$0106-\mathrm{Z}$

Neumann, A. P. \& Wagner, A. (2017). Reverberations of a Marital Education Program: The Moderators' Perception. Paidéia, 27(Suppl. 1), 466-474. https://doi.org/10.1590/1982-432727s1201712

Owen, J. J., Manthos, M., \& Quirk, K. (2013). Dismantling study of prevention and relationship education program: The effects of a structured communication intervention. Journal of Family Psychology, 27(2), 336-341. https://doi org/10.1037/a0031597

Owen, J. J., Rhoades, G. K., Stanley, S. M., \& Markman, H. J. (2011). The role of leaders' working alliance in premarital education. Journal of Family Psychology, 25(1), 49-57. https://doi.org/10.1037/a0022084

Quirk, K., Owen, J. J., Inch, L. J., France, T., \& Bergen, C. (2014). The alliance in relationship education programs. Journal of Marital and Family Therapy, 40(2), 178-192. https://doi.org/10.1111/jmft.12019

Wadsworth, M. E. \& Markman, H. J. (2012). Where's the action? Understanding what works and why in relationship education. Behavior Therapy, 43(1), 99-112. https://doi.org/10.1016/j.beth.2011.01.006

Wagner, A., Neumann, A.P., Mosmann, A. P., Levandowski, D. C., Falcke, D., Zordan, E. P., ..., \& Scheeren, P. (2015). 'Viver a dois: Compartilhando esse desafio': Uma proposta psicoeducativa para casais. Porto Alegre: Sinodal.

Williamson, H. C., Altman, N., Hsueh, J., \& Bradbury, T. N. (2016). Effects of relationship education on couple communication and satisfaction: A randomized controlled trial with low-income couples. Journal of Consulting and Clinical Psychology, 84(2), 156-166. https://doi.org/10.1037/ccp0000056

Zemp, M., Merz, C. A., Nussbeck, F. W., Halford, W. K., Gmelch, M .S., \& Bodenmann, G. (2017). Couple relationship education: A randomized controlled trial of professional contact and self-directed tools. Journal of Family Psychology, 31(3), 347-357. https://doi.org/10.1037/fam0000257

Contribuição individual de cada autor para a pesquisa e para o manuscrito:

O primeiro autor coletou os dados. Ambos os autores colaboraram com a análise dos dados e com a redação do artigo.

Todos os autores leram e aprovaram a versão final do manuscrito.

Dados dos autores:

Angélica Paula Neumann - Doutora, Universidade Regional Integrada do Alto Uruguai e das Missões.

Adriana Wagner - Doutora, Universidade Federal do Rio Grande do Sul.

Endereço para correspondência:

Angélica Paula Neumann

Rua Conselheiro Sperhacke, 320/201

99709-250 Erechim, RS, Brasil

<angelicaneumann@gmail.com>

Recebido em: 04. 12.2017

Aceito em: 05.07.2018 